\title{
European Journal of Government and Economics
}

journal homepage: www.ejge.org

ISSN: 2254-7088

\section{The short selling regulation in the European Union:}

\section{Assessing the authorization granted for the European Securities and Markets Authority to prohibit short selling}

\author{
Matias Huhtilainen ${ }^{a, *}$ \\ a University of Eastern Finland, Finland. \\ * Corresponding author at: University of Eastern Finland, Yliopistokatu 2. 80100 Joensuu, Finland. \\ matias.huhtilainen@uef.fi
}

Article history. Received 7 May 2016; first revision required 12 December 2016; accepted 27 January 2017.

\begin{abstract}
This paper discusses the renewed short selling regulation (Regulation (EU) No 236/2012) in the European Union. The focus is on the provisions that deal with prohibiting short selling in exceptional market circumstances. The Regulation further enforces certain obligations to report and disclose short positions. It is concluded that banning short selling is not an effective tool to contain extreme price volatility. The difference-in-differences regression and repeated measures GLM were used to test whether short selling bans were successful in containing volatility of those Spanish and Italian stocks that were subject to two back-to-back prohibitions during the years 2011-2013. The results are consistent with the majority of previous research, suggesting that the effectiveness of short sale constraints in reducing volatility is limited at best. Furthermore, there are evidence of counterproductive effects: constraints on short selling may actually increase volatility as well as deteriorate liquidity. However, based on theory and previous studies, reporting and disclosure requirements shall be favored provided they improve market efficiency as well as supervisory work of regulatory bodies.
\end{abstract}

Keywords. Short selling; Regulation; Intervention; Treatment effect

JEL classification. G01; G18; K20

\section{Introduction}

The financial crisis in 2008 initiated a global recession which eventually, but only partly contributed to the sovereign debt crisis in the Eurozone. It was argued in the Liikanen Report (2012) that these events (should) provide impetus for the legislative reforms concerning the financial and capital markets in the European Union. The group further emphasized that even though the reforms are, by nature, pre-emptive, the aim shall be in providing authorities such tools that would effectively control the already existing market disorders. The distinctive objective is to create a market infrastructure in which the efficient capital allocation would not be suppressed, but at the same time systemic risks could be monitored and managed properly in order to protect the economic stability of the Member States. In consequence, the European Commission has 
proposed about 30 sets of rules since 2010 regarding the common financial and capital markets in the European Union (EU). The most essential reforms include the implementation of Basel 3 framework into the EU banking regulation (CRD IV) as well as in further accordance with global collaboration the European Market Infrastructure Regulation (EU) No 648/2012 and Alternative Investment Fund Managers Directive (2011/61/EU), which provide comprehensive rules for overthe-counter derivatives trading and for the business activity conducted by property, private equity, commodity and hedge funds. It is noteworthy though, that this type of reactive regulatory work should not be viewed as anything unique. As Dobravolskas and Seiranov (2011) address, the "regulatory reforms are reaction to market failures" and the evolution of regulation can be comprehended as a long regulatory cycle where "periods of tightened regulation are changed with lax regulation or deregulation". Quite interestingly, the previous financial markets regulatory cycle in the EU from 1999 to 2004 also addressed issues such as supervision, supranational regulation and harmonized frameworks (Quaglia 2007), but was unable to provide sufficient systemic resiliency against the upcoming meltdown in 2008.

Relevant to this paper, however, is the report "Model for a Pan-European Short Selling Disclosure Regime Regulation" by the Committee of European Securities Regulators (2010). In the immediate aftermath of Lehman Brothers collapse both the United States (US) Securities and Exchange Commission and the regulatory body of the United Kingdom (UK), the Financial Services Authority, had temporarily banned short selling in order to protect the markets and reduce downward pressure on prices. The ban covered 29 financial stocks in London Stock Exchange and - eventually - over 900 stocks in the US. Subsequently, 24 other countries enforced varying constraints on short selling between September and October in 2008. (Hansson and Fors 2009; Beber and Pagano 2013). Following the diversified measures by regulatory bodies, CESR remarked in the report that market participants had been negatively affected by the numerous and varying rulebooks across market places while allowing other, usually larger institutional market participants to benefit from regulatory arbitrage. The report formed the basis for the legislative process that would eventually lead to the introduction of Regulation (EU) No 236/2012 on Short Selling and Certain Aspects of Credit Default Swaps, which became fully applicable on 1 November 2012. The regulatory ambition has been to (i) increase the transparency of short positions; (ii) strengthen the stability of sovereign debt markets; (iii) provide sufficient tools for authorities to intervene markets in exceptional times; and to (iv) ensure a proper coordination between national authorities and European Securities and Markets Authority (ESMA).

The focus of this study is on the short sale constraints from both legal and empirical perspectives. First, the key provisions of the new Regulation regarding short sale constraints, reporting requirements and supervisory work are addressed. Secondly, theory on price formation and the impact of trading constraints is discussed. Lastly, the difference-in-differences regression and repeated measures GLM are applied to test whether the short selling bans conducted in Spain and Italy were successful in containing price volatility during the years 2011-2013. In contrast to a trading venue where only one-time intervention is observed, both Spain and Italy enforced two subsequent short selling bans on financial stocks following each other in a relatively 
short period of time. This provides a research design where the same treatment (=short selling ban) is repeated twice on same patients (=financial stocks), allowing any repetitive intervention effect to be observed with higher degree of certainty. The success of these constraints is concluded by reflecting the empirical results against the arguments that were used to advocate the said measures. As the bans in Spain and Italy were explicitly justified by the excessive price volatility, a logical research problem is therefore to assess whether the bans issued by the regulatory bodies were successful in containing the volatility of those financial stocks that were concerned by the prohibitions. Subsequently, a conclusion of the necessity of such powers granted for market authorities is also drawn.

\section{The practice of short selling under new regulatory regime}

The first significant revision is the prohibition of naked short selling. According to Preamble 18 of the Regulation the "uncovered short selling of shares and sovereign debt is sometimes viewed as increasing the potential risk of settlement failure and volatility", and in order to reduce such risks "it is appropriate to place proportionate restrictions on uncovered short selling of such instruments". In consequence, the Regulation obliges to either borrow or to arrange the borrowing or have an arrangement with a third party that has confirmed that the securities have been located before entering into a short position. Thus, prohibition of naked positions applies equally to equity and sovereign debt instruments. Concerns regarding the stability of sovereign debt markets on one hand and the excessive sovereign debt of certain member states on the other have been highlighted since the escalation of European debt crisis. Due to the possible adverse impact on debt market stability, regulation now prohibits purchasing credit default swaps without having a long position in underlying sovereign debt instrument. Thus, sovereign credit default swaps shall be based on the insurable interest principle: only legitimate reason to enter into a CDS contract is to hedge against the default risk of the issuer, which naturally requires an ownership in the underlying security. Conversely, should a natural or a legal person buy a credit default swap without purchasing the underlying debt instrument first, it would be in his best interest that the issuer defaults.

Further practical change is the obligation to report and disclose significant net short positions to national competent authorities (NCA) and to the public, respectively. Apart from exemptions granted for market makers and authorized primary dealers, the reporting requirement applies to every market participant, but in respect to a predefined threshold. A significant net short position in shares equals or exceeds 0.2 per cent of issued share capital. Notification obligation further applies to every 0.1 per cent change above the threshold. Respective initial thresholds in sovereign debt are set at 0.1 and 0.5 per cent. The former applies if the total outstanding issued debt does not exceed $€ 500$ billion, and vice versa. However, the threshold of 0.5 per cent may apply irrespective to the value of outstanding debt provided there is a liquid futures market for that particular sovereign debt. Moreover, additional incremental levels are set at 50 per cent of the initial threshold and shall be each 0.05 per cent change above the initial notification threshold of 
0.1 per cent starting at 0.15 per cent, as well as each 0.25 per cent change above the initial threshold of 0.5 per cent starting at 0.75 per cent.

The purpose of the reporting obligation is twofold. First, it enables ESMA to monitor market moves in general and large positions in particular, and in consequence manage risks that dwell within. Secondly, NCAs are required to disclose reported net short positions in shares in a comprehensive and easily accessible manner, which shall be expected to contribute to more transparent market fluctuations. The disclosure threshold is set at 0.5 per cent of issued share capital, and each 0.1 per cent move above the initial threshold in addition is further disclosed. Christophe et al. (2004) suggest that authorities should disclose more detailed and timely information on short positions as it would provide more accurate picture of the market sentiment, thus increasing the pricing efficiency. Based on trading data from 913 Nasdaq-listed stocks, they concluded that short sellers are information-oriented traders: results showed that abnormal short selling activity before the earnings announcement was significantly linked with the stock price reaction after the earnings went public, indicating a positive relationship between overvalued stocks and short sale volume.

Lastly, the Regulation provides NCAs an authorization to enforce temporary bans or introduce other constraints of similar effect, provided it notifies ESMA beforehand, which then coordinates and implements the proposed measures. However, according to Article 28(1), ESMA is permitted to disregard any NCA and directly order emergency measures and conduct direct operational decisions anywhere in the European Economic Area. Intervention may only take place, however, if market conditions favor taking measures. Such conditions pose an apparent threat to the functionality of financial markets or to the stability of the whole or part of the financial system in the Union ("cross-border implications"). Interestingly, the European Court of Justice (ECJ) rejected the UK's lawsuit in January 2014. In the case "C-270/12, United Kingdom of Great Britain and Northern Ireland v. Council of the European Union, European Parliament", the UK argued that emergency powers handed to ESMA were illegal and that constraints on short selling have a negative impact on market efficiency. The ECJ ruled that the new powers were compatible with EU law, dismissing the legal case in its entirety.

\subsection{Which Circumstances Count as "Exceptional"?}

The legal mandate for the competent authority to prohibit or impose conditions to natural or legal persons entering into a short sale is provided in Article 20(2). Measures are further applicable to transactions concerning all financial instruments and transactions other than short sales, provided the pursued effect of the transaction is to confer a financial advantage in the event of a decrease in price or value of another financial instrument. In accordance with Article 20(1)(a), the definition of exceptional circumstances is proportional to the market preconditions that include adverse events or developments which constitute a serious threat to financial stability or to market confidence in one or more Member States.

Article 24(1) of Commission Delegated Regulation (EU) No 918/2012 (referred to hereinafter 
if not mentioned otherwise) supplements the Regulation with specific characteristics of adverse events and developments. They include any act, result, fact, or event that is or could reasonably be expected to cause serious financial, monetary or budgetary problems which may lead to financial instability concerning a Member State or a bank and other financial institutions deemed important to the global financial system; a rating action or a default by any Member State or banks and other financial institutions deemed important to the global financial system that causes or could reasonably be expected to cause severe uncertainty about their solvency; substantial selling pressures or unusual volatility causing significant downward spirals in any financial instrument related to any banks and other financial institutions and sovereign issuers deemed important to the global financial system; any relevant damage to the physical structures of important financial issuers, market infrastructures, clearing and settlement systems, and supervisors which may adversely affect markets in particular where such damage results from a natural disaster or terrorist attack; and any relevant disruption in any payment system or settlement process, in particular when it is related to interbank operations, that causes or may cause significant payments or settlement failures or delays within the Union payment systems, especially when these may lead to the propagation of financial or economic stress in a bank and other financial institutions deemed important to the global financial system or in a Member State.

Lastly, additional consideration should take into account the violent intra-day price changes. Thus, should a price of a financial instrument fall significantly during a single trading day, the national competent authority is handed powers to prohibit or restrict short selling in order to prevent a disorderly decline in the price of the financial instrument (Article 23(1)). A liquid share is determined to experience a significant fall in price when close-to-close return yields -10 per cent or more. This applies to illiquid shares as well, provided the company is included in the main national equity index and is the underlying for a derivative contract traded in a trading venue. Otherwise a significant decrease in price is defined as 20 per cent or more for a share which price is $€ 0.50$ or higher, or the equivalent in the local currency. In all other cases, the daily decrease in value shall be 40 per cent or more to be considered significant. For sovereign and corporate bonds, increases of 7 and 10 per cent in the yield, respectively, are deemed to be significant falls in value (Article 23(2-3)).

Quite interestingly, certain market conditions that would be later identified by the Regulation were already broadly taken into account in a public statement ESMA released on 11 August 2011. In it ESMA noted that the European financial markets had been very volatile in the preceding weeks and that the "developments have raised concerns for securities markets regulators across the European Union". The following day Spain, France, Belgium and Italy prohibited short selling with several publicly traded financial and insurance companies. The bans were originally set to last either 15 days or until further notice. Belgium and France lifted the ban on 11 February 2012. France did not validate the decision, but Belgium pointed to the reduced market volatility. Greece had already banned short selling on 9 August 2011. The Greek regulator HCMC made the decision while taking into account the conditions prevailing in the Greek markets. After several extensions, the ban was eventually lifted on 15 July 2013. 
However, the regulatory bodies in mainland Europe were not the first ones to implicate a relationship between high volatility and short selling. On 19 September 2008, SEC described the market conditions as a period of unusual and extraordinary market volatility, while it appeared that "unbridled short selling is contributing to the recent, sudden price declines in the securities of financial institutions unrelated to true price valuation." A day earlier FSA justified its own ban by stating that the measurements would protect and stabilize the markets. The Chief Executive Hector Sants was quoted that "while we still regard short selling as a legitimate investment technique in normal market conditions, the current extreme circumstances have given rise to disorderly markets". Australian market authority ASIC (2012) remarked how during the financial crisis countries around the world took steps to strengthen their financial systems due to the widespread concern that short selling was contributing to market volatility and putting enough pressure on market confidence to be systematically relevant to the global financial system and economy.

\subsection{Remarks on Price Discovery Process}

Among academics and market participants, the debate about trading constraints is partly preoccupied with interest on their impact on price discovery process and allocation of capital. Miller (1977) proposed that overvaluation of stocks follows circumstances where short selling is prohibited, yet investors hold heterogeneous beliefs on the stock's fair value. Constraints on short selling only allow bullish or optimistic views to be reflected into security prices, provided that current shareholders are indifferent of owning that stock, while bearish investors who do not own shares cannot participate in trading. Boulton and Braga-Alves (2010) provided results consistent with Miller's conclusion about the linkage between constraints and overpricing of securities. Hence, considering the previously discussed statements regulatory bodies released during the global wave of interventions, the following problematization of causality shall be assessed: either short selling is the reason and securities trading below their fair values the result; or securities are being aggressively shorted because their current market value does not correspond with the underlying fundamentals and future expectations.

Under efficient market conditions, the first scenario seems unlikely. The effect of downward price manipulation would disappear due to the increased demand for the respective security trading at below its fair value. Baker and Wurgler (2006) interpret efficient markets as a competition among rational investors eventually leading to equilibrium in which prices equal the rationally discounted value of expected cash flows. The latter scenario is further supported by Diamond and Verrecchia (1987) who argued that due to the relatively high costs associated with short sales, only informed traders, and specifically those traders with bearish view, engage in short selling. Reed (2003) tested the Diamond-Verrecchia-model and provided results consistent to those by Diamond and Verrecchia. Werner (2010) points out to evidence on the negative relationship between changes in short interest and subsequent stock returns, suggesting that short sellers are at least somewhat rational participants whose decision making is based on 
fundamental valuation. However, short selling serves other practical purposes as well. Namely, as hedging positions or portfolios, and as a part of market makers' toolkit (Gregoriou 2012).

On the contrary, several studies dismiss the assumption of perfect rationality. Biased investors' decision-making is correlated with the rest of the markets, thus leading to irrational behavior (Huang et al. 2015). Lee et al. (2002) find excessive returns to be correlated with shifts in sentiment. They further conclude that bearish turnover in sentiment leads to increased volatility along with decreased future returns. Brown and Cliff (2005) also find a positive relationship between pricing errors and market sentiment; periods of high sentiment are followed by low longterm future returns. Based on the presented evidence, a case could be made for the short selling prohibitions that took place in the aftermath of financial crisis. If during market turmoil herd behavior builds up and decision making among market participants becomes highly correlated, aggressive short selling may strengthen the excessive downward pressure, thus pushing the security prices below their intrinsic values for a considerable amount of time. Adverse effects are numerous, such as margin calls and enforced collateral sales, which would further deepen the pro-cyclicality effect.

\subsection{Market Effects of Short Selling Constraints}

The evidence regarding the relationship between short selling and volatility, liquidity and price efficiency is somewhat consistent. Charoenrook and Daouk (2005) provide results which point to less volatile aggregate returns as well as greater liquidity in the markets when short selling is not subject to restrictions. Stocks with higher short-sale constraints are affected by deteriorated price efficiency and vice versa; neither do relieved constraints lead to price instability or extreme negative returns (Saffi and Sigurdsson 2011; Bai et al. 2006; Boehmer and Wu 2013; McKenzie 2012). Boehmer et al. (2013) and Beber and Pagano (2013) concluded that constraints reduce liquidity; this is particularly undesirable in a crisis situation where bid-ask-spreads are already large.

Evidence indicating failure of the bans during the financial crisis and later in Europe during the years 2011 and 2012 have been provided by Saastamoinen and Suhonen (2013); Helmes et al. (2011); Lobanova et al. (2010); Boulton and Braga-Alves (2012). In addition, Bernal et al. (2014) concluded that all types of short sale constraints inflict negative impact on market efficiency and that no constraint is effective against price decline. However, they proposed that naked short selling prohibition is the least damaging one from the perspective of market efficiency.

On the other hand, Chang et al. (2007) find less positively skewed returns as well as increased volatility for individual stocks coincidental to short sale volume. Furthermore, Lecce et al. (2008) and Setzu and Marchesi (2006) present evidence that suggest increased volatility in relation to short selling. Appel and Fohlin (2010) argue that short selling bans in 2008-2009 improved market liquidity. Bris et al. (2007) presented results that suggested less negatively skewed returns in countries where short selling was prohibited. They further propose that short selling bans may alleviate panic in the markets. 
It is worth noting that the bans were targeted distinctly at financial stocks, which is suggestive of concerns on contagion of losses subsequent to liquidity run in a highly concentrated and interconnected network of financial institutions. The SEC press release on 19 September 2008 further implicated those concerns as SEC suggested there was an essential link between the stock price and confidence in the financial institution and that institutions were particularly depended on the confidence of their trading counterparties in the conduct of their core business. Vitali et al. (2011) provide evidence on the global structure of the control network of transnational corporations. They further conclude that while the financial network is seemingly robust in a nonvolatile environment, in bad times firms go into distress simultaneously due to the contagion effect in a densely connected system.

\section{Did the two subsequent bans in Italy and Spain contain volatility?}

According to theory of government failure, poor public policies generate counterproductive effects, which lead to an environment that is more inefficient or otherwise non-optimal, vis-à-vis, to the preceding situation where the intervention did not take place (Datta-Chaudhuri 1990). Thus, good goals per se cannot be satisfactory if the costs exceed the benefits. Rent control, for instance, is suggested to distort the residential construction and lower the housing quality. The target (an affordable residential district) would be achieved but only with costs that are not being sufficiently compensated (Moon and Stotsky 1993). Interestingly, the Regulation clearly takes into account the necessity to compare benefits and costs before conducting any interventions: Article 20(1)(b) permits competent authorities to act only when the "measure is necessary to address the threat and will not have a detrimental effect on the efficiency of financial markets which is disproportionate to its benefits".

The SEC chairman Christopher Cox stated in an interview on 31 December 2008 that, quote, "Knowing what we know now, I believe on balance, the commission would not do it (short-sale ban on financials) again. The costs appear to outweigh the benefits." Whether market authorities are affected by action bias during market turmoil is worth considering. Notable market panic could add further pressure simply to do anything in order to satisfy the action-seeking public. Should taking measures become the priority in itself rather than the actual outcome, it could heighten the risk of intervention's "detrimental effects disproportionate to its benefits".

Although the methodical approach is similar to Saastamoinen and Suhonen (2013), only Spanish and Italian stocks are considered for they were "treated" twice in both countries, as explained earlier. The paper by Saastamoinen and Suhonen on the other hand studies the first (and onetime) ban conducted in Spain, France, Belgium and Italy from 12 August 2011. The treatment indicator is defined in Table 1. The treatment indicator values 0 and 1 indicate non-treated and treated time periods, respectively. The timetable is split up in five portions using the exact dates each short selling ban was first introduced and later lifted in Spain and Italy. The non-treatment periods were composed to be as identical in duration as possible. 
Table 1. Treatment indicator.

\begin{tabular}{cccccc} 
& $\mathbf{0}$ & $\mathbf{1}$ & $\mathbf{0}$ & $\mathbf{1}$ & $\mathbf{0}$ \\
\hline \multirow{2}{*}{ Spain } & $01 / 02 / 2011$ & $12 / 08 / 2011$ & $16 / 02 / 2012$ & $23 / 07 / 2012$ & $01 / 02 / 2013$ \\
& $11 / 08 / 2011$ & $15 / 02 / 2012$ & $22 / 07 / 2012$ & $31 / 01 / 2013$ & $31 / 08 / 2013$ \\
\hline \multirow{2}{*}{ Italy } & $01 / 02 / 2011$ & $12 / 08 / 2011$ & $25 / 02 / 2012$ & $23 / 07 / 2012$ & $15 / 09 / 2012$ \\
& $11 / 08 / 2011$ & $24 / 02 / 2012$ & $22 / 07 / 2012$ & $14 / 09 / 2012$ & $31 / 03 / 2013$ \\
\hline
\end{tabular}

Similarly to the above-mentioned paper, though, the possible treatment impact on price volatility is estimated on close-to-close prices; see Figure 1. The (potential) treatment effect. is observed from the post intervention difference-in-differences between the treated group A and control group $B$.

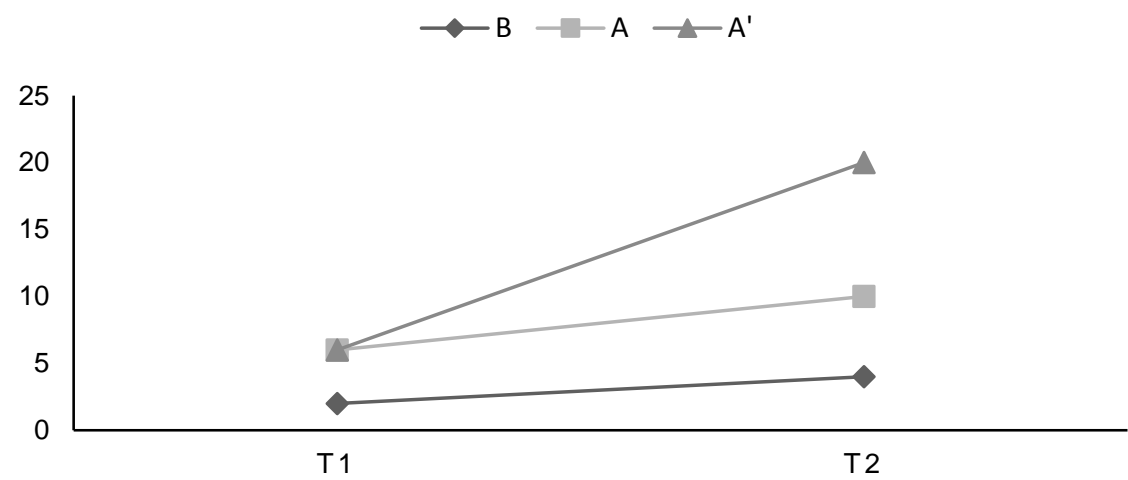

Figure 1. (Potential) treatment effect observed from the post intervention difference-in-differences between the treated group A and control group B.

\subsection{Data and Methodology}

The data contain those stocks that were subject to the first ban in Spain and Italy. Stocks under the scope of the second ban were the same in Italy, but in Spain every listed company in the Madrid Stock Exchange was concerned. However, only those 16 stocks that were affected by the first ban are included. In addition, the Italian financial market authority CONSOB imposed a oneday prohibition on four stocks on 27 February 2013, but this was not taken into account. A control group was formed with 30 non-treated Swedish, Finnish, Dutch, Irish, Slovene, Austrian, Maltese, Cypriot, German and Portuguese financial services companies in respect to a considerable market value as well as sufficient liquidity and trading volume.

Due to the mergers and acquisitions the number of companies in the data did not remain constant. The following companies in Spain were delisted at some point between December 2011 and August 2013: Banca Cívica, Banco de Valencia, Banco Español de Crédito, Banco Pastor, Caja de Ahorros del Mediterráneo. In Italy, Credito Artigiano was acquired by Credito Valtellinese in September 2012. Additionally, Bankia launched an IPO in June and the shares began trading on 20 July 2011. Banca Cívica went public on 21 July 2011. The number of observations (trading 
days) for Bankia and Banca Cívica preceding the first ban totaled 17 and 16, respectively. The number of stocks in the control group remained the same. Due to the different treatment cutoff points at $t_{n}$ between Italian and Spanish markets, the average group volatility for control stocks is computed twice using both Spain's and Italy's exact dates, see Table 1.

Stock's daily log return $r$ is calculated with close-to-close prices (adjusted with dividends and splits):

$$
r_{t}=\ln \left(\frac{p_{t}}{p_{t-1}}\right)
$$

where $p_{t}$ denotes asset price at time $t$.

The realized variance (RV) method is followed to compute the stock's realized volatility as the sum of daily squared log returns. The stock's average $R \vee$ for each time period is further obtained by dividing the sum with the number of close-to-close returns:

$$
\overline{r v}=\frac{\sum_{t=1}^{n} r_{t}^{2}}{n}
$$

The average group RV for each time period is then computed by dividing the sum of mean $\mathrm{RVs}$ with number of companies belonging to that group in question:

$$
\overline{R V_{l, t}}=\frac{\sum_{i=1}^{n} \overline{r v_{i}}}{N}
$$

Table 2 presents the average group RVs. Time period indicator values are as described in Table 1. As noted earlier, control group volatility is estimated twice using both Spain's and Italy's exact treatment moments

Table 2. Average group RVs.

\begin{tabular}{lccccc} 
& $\mathbf{0}$ & $\mathbf{1}$ & $\mathbf{0}$ & $\mathbf{1}$ & $\mathbf{0}$ \\
\hline Spain & .000420409 & .001664344 & .001262440 & .002076911 & .002330436 \\
Italy & .000803200 & .001699800 & .004650600 & .001834200 & .000576400 \\
\hline Control Spain & .001321801 & .001609780 & .000928883 & .000878727 & .000911369 \\
Control Italy & .001321801 & .001614430 & .000877246 & .001214762 & .000722796 \\
\hline
\end{tabular}




\subsubsection{Difference-in-Differences Framework}

The estimate of difference-in-differences between treatment and control groups after the treatment is obtained from

$$
\left(\mu_{11}-\mu_{10}\right)-\left(\mu_{01}-\mu_{00}\right)
$$

where $\mu_{i t}$ is the (mean) outcome of group $i$ at time $t$. The dummy value 0 in subscript either denotes control group or pre-treatment period, and vice versa.

Table 3. Volatility during bans.

\begin{tabular}{rcrcc} 
& \multicolumn{2}{c}{ SPAIN } & \multicolumn{2}{c}{ ITALY } \\
\hline & First ban & Second ban & First ban & Second ban \\
$\left(\mu_{11}-\mu_{10}\right)$ & .020292487 & .010042306 & .012888638 & -.025367707 \\
$\left(\mu_{01}-\mu_{00}\right)$ & .003765482 & -.000834253 & .003823385 & .005235096 \\
\hline$D-D$ estimate & .016527005 & .010876559 & .009065253 & -.030602803 \\
\hline
\end{tabular}

As shown in Table 3, volatility in Spain exceeded the preceding period's volatility during both bans. The time period under the second ban was less volatile in Italy compared to the preceding non-ban period.

The treatment effect as the coefficient of the interaction $\beta_{3}$ is obtained from the difference-indifferences linear regression model:

$$
y_{i}=\beta_{0}+\beta_{1}\left(\text { treat }_{i}\right)+\beta_{2}\left(\text { after }_{i}\right)+\beta_{3}\left(\text { treat }_{i} \times \text { after }_{i}\right)+\varepsilon_{i},
$$

where: $y_{i}=$ the treatment effect; treat $_{i}=1$ if in treatment group; treat $_{i}=0$ if in control group; after $_{i}=1$ if after the introduction of treatment; after $_{i}=0$ if before the introduction of treatment. Baseline is the non-treatment time period which is followed by a period of short sale prohibition (Follow Up). The upper section of the table merely reports the number of companies in each group during time period $i$. Treatments effects for both Spain and Italy are shown in Table 4 and Table 5 , respectively. Neither treatment significantly reduced targeted groups' volatility relative to the change in control group stocks; see Table 5. 
Table 4. The treatment effects for both bans in Spain.

First Ban

Second Ban

\begin{tabular}{|c|c|c|c|c|}
\hline & & \\
\hline & Baseline & Follow Up & Baseline & Follow Up \\
\hline Control & 30 & 30 & 30 & 30 \\
\hline Spain & 16 & 16 & 15 & 14 \\
\hline Total & 46 & 46 & 45 & 44 \\
\hline $\mathrm{R}^{2}$ & 0.0256 & & 0.0456 & \\
\hline & Baseline & Follow Up & Baseline & Follow Up \\
\hline Control & 0.001 & 0.002 & 0.001 & 0.001 \\
\hline Spain & 0.000 & 0.002 & 0.001 & 0.002 \\
\hline Diff & -0.001 & 0.000 & 0.000 & 0.001 \\
\hline Diff-in-Diff & & 0.001 & & 0.001 \\
\hline Std. Error & & 0.001 & & 0.001 \\
\hline $\mathrm{t}$ & & 0.80 & & 0.97 \\
\hline$P>|t|$ & & $0.428^{* *}$ & & $0.337^{* *}$ \\
\hline
\end{tabular}

Table 5. The treatment effects for both bans in Italy.

First Ban Second Ban

\begin{tabular}{lrrrr}
\hline & Baseline & Follow Up & Baseline & Follow Up \\
Control & 30 & 30 & 30 & 30 \\
Italy & 29 & 29 & 29 & 29 \\
Total & 59 & 59 & 59 & 59 \\
R-square & 0.0210 & & 0.0292 & \\
\hline & Baseline & Follow Up & Baseline & Follow Up \\
Control & 0.001 & 0.002 & 0.001 & 0.001 \\
Italy & 0.001 & 0.002 & 0.005 & 0.002 \\
Diff & -0.001 & 0.000 & 0.004 & 0.001 \\
Diff-in-Diff & & $\mathbf{0 . 0 0 1}$ & & $\mathbf{- 0 . 0 0 3}$ \\
Std. Error & & $\mathbf{0 . 0 0 1}$ & & $\mathbf{0 . 0 0 3}$ \\
t & & $\mathbf{0 . 6 8}$ & & $\mathbf{- 0 . 9 9}$ \\
P>|t| & & $\mathbf{0 . 5 0 0 * *}$ & & $\mathbf{0 . 3 2 7 * *}$ \\
\hline
\end{tabular}

Notes. * Means and Standard Errors are estimated by linear regression. ** Inference: *** $p<0.01 ;{ }^{* *} p<0.05 ;{ }^{*} p<0.1$

\subsubsection{Repeated Measures GLM}

In contrast to computing the average daily RV of control group stocks for each time period twice using both Spain's and Italy's exact intervention moments separately, the dates that divide control group data into five subsequent portions are redefined as to concurrently respond both Italian and Spanish time periods as inclusively as possible. It is thus important to address that "manipulating" data in this manner will produce at least somewhat inaccurate results. Table 6 shows the redifined 
time periods, and Table 7 some descriptive statistics. The model omits those stocks that have missing values in either time period. Therefore $N$ is constant for each group throughout the dataset.

Table 6. Redefined time periods.

\begin{tabular}{lccccc} 
Control & $\mathbf{1}$ & $\mathbf{2}$ & $\mathbf{3}$ & $\mathbf{4}$ & $\mathbf{5}$ \\
\hline Time Period & $01 / 02 / 2011$ & $12 / 08 / 2011$ & $25 / 02 / 2012$ & $23 / 07 / 2012$ & $24 / 11 / 2012$ \\
& $11 / 08 / 2011$ & $24 / 02 / 2012$ & $22 / 07 / 2012$ & $23 / 11 / 2012$ & $14 / 06 / 2013$ \\
\hline
\end{tabular}

Table 7. Descriptive statistics for the redefined time periods.

\begin{tabular}{cccc} 
& Group & Mean & N \\
\hline Time 1 & Spain & .0003886263 & 13 \\
& Italy & .0008225523 & 28 \\
& Control & .0013218015 & 30 \\
& & & \\
Time 2 & Spain & .0008748838 & 13 \\
& Italy & .0017307628 & 28 \\
& Control & .0016144301 & 30 \\
& & & \\
Time 3 & Spain & .0011986207 & 13 \\
& Italy & .0047757355 & 28 \\
& Control & .0008772460 & 30 \\
& & & \\
Time 4 & Spain & .0021373749 & 13 \\
& Italy & .0018406059 & 28 \\
& Control & .0010071807 & 30 \\
& & & \\
Time 5 & Spain & .0023304357 & 13 \\
& Italy & .0005764257 & 28 \\
& Control & .0007745044 & 30 \\
\hline
\end{tabular}

The following analysis includes one between-subjects factor "Group" with three levels (Spain, Italy and Control group) and one within-subjects factor "Time" with five levels (time periods 1 to 5). The interest is on whether the difference between levels of Group is different when comparing within-subjects factor levels 2 and 1, 4 and 3 and 5 and 1. Contrast coefficients matrix of each possible pairwise comparison of Group levels is thus:

$$
L=\left(\begin{array}{ccc}
1 & -1 & 0 \\
1 & 0 & -1 \\
0 & 1 & -1 \\
0 & -1 & 1 \\
-1 & 1 & 0 \\
-1 & 0 & 1
\end{array}\right)
$$


where L1: (1) Spain (-1) Italy, L2: (1) Spain (0) Control, L3: (0) Italy (1) Control, L4: (0) Control (1) Italy, L5: (-1) Italy (1) Spain and L6: (-1) Control (0) Spain.

For within-subjects factor Time, levels 2 and 4 notate the first and second bans, respectively. Interaction contrasts for Group levels and difference between levels 2 and 1, 4 and 3 and 5 and 1 of Time are provided. Thus, for L2 "Time 2 v Time 1": (2Spain - 2Control) - (1Spain - 1 Control $)=.000$. The last contrast for the difference between last and first time period is merely anecdotal, as if whether there was a significant difference in volatility after two nearly consecutive prohibition periods vis-à-vis to the base point when no actions had been taken by the authorities.

Table 8. Contrast results.

Time 2 v Time 1 Time 4 v Time 3 Time 5 v Time 1

\begin{tabular}{|c|c|c|c|c|}
\hline \multirow[t]{7}{*}{ L1 } & Contrast Estimate & .000 & .004 & .002 \\
\hline & Hypothesized Value & 0 & 0 & 0 \\
\hline & Difference (Est. - Hypothesized) & .000 & .004 & .002 \\
\hline & Std. Error & .001 & .003 & .001 \\
\hline & Sig. & .477 & .161 & .037 \\
\hline & $95 \%$ Conf. for Diff. Lower Bound & -.002 & -.002 & .000 \\
\hline & $95 \%$ Conf. for Diff. Upper bound & .001 & .009 & .004 \\
\hline \multirow[t]{7}{*}{ L2 } & Contrast Estimate & .000 & .001 & .002 \\
\hline & Hypothesized Value & 0 & 0 & 0 \\
\hline & Difference (Est. - Hypothesized) & .000 & .001 & .002 \\
\hline & Std. Error & .001 & .003 & .001 \\
\hline & Sig. & .741 & .766 & .017 \\
\hline & $95 \%$ Conf. for Diff. Lower Bound & -.001 & -.005 & .000 \\
\hline & 95 \% Conf. for Diff. Upper bound & .001 & .006 & .005 \\
\hline \multirow[t]{7}{*}{ L3 } & Contrast Estimate & .001 & -.003 & .000 \\
\hline & Hypothesized Value & 0 & 0 & 0 \\
\hline & Difference (Est. - Hypothesized) & .001 & -.003 & .000 \\
\hline & Std. Error & .000 & .002 & .001 \\
\hline & Sig. & .187 & .157 & .710 \\
\hline & $95 \%$ Conf. for Diff. Lower Bound & .000 & -.007 & -.001 \\
\hline & $95 \%$ Conf. for Diff. Upper bound & .002 & .001 & .002 \\
\hline \multirow[t]{7}{*}{ L4 } & Contrast Estimate & -.001 & .003 & .000 \\
\hline & Hypothesized Value & 0 & 0 & 0 \\
\hline & Difference (Est. - Hypothesized) & -.001 & .003 & .000 \\
\hline & Std. Error & .000 & .002 & .001 \\
\hline & Sig. & .187 & .157 & .710 \\
\hline & $95 \%$ Conf. for Diff. Lower Bound & -.002 & -.001 & -.002 \\
\hline & $95 \%$ Conf. for Diff. Upper bound & .000 & .007 & .001 \\
\hline \multirow[t]{7}{*}{ L5 } & Contrast Estimate & .000 & -.004 & -.002 \\
\hline & Hypothesized Value & 0 & 0 & 0 \\
\hline & Difference (Est. - Hypothesized) & .000 & -.004 & -.002 \\
\hline & Std. Error & .001 & .003 & .001 \\
\hline & Sig. & .477 & .161 & .037 \\
\hline & $95 \%$ Conf. for Diff. Lower Bound & -.001 & -.009 & -.004 \\
\hline & $95 \%$ Conf. for Diff. Upper bound & .002 & .002 & .000 \\
\hline \multirow[t]{7}{*}{ L6 } & Contrast Estimate & .000 & -.001 & -.002 \\
\hline & Hypothesized Value & 0 & 0 & 0 \\
\hline & Difference (Est. - Hypothesized) & .000 & -.001 & -.002 \\
\hline & Std. Error & .001 & .003 & .001 \\
\hline & Sig. & .741 & .766 & .017 \\
\hline & $95 \%$ Conf. for Diff. Lower Bound & -.001 & -.006 & -.005 \\
\hline & $95 \%$ Conf. for Diff. Upper bound & .001 & .005 & .000 \\
\hline
\end{tabular}


Table 8 presents the contrast results. No statistical significance for the differences between levels of Group is found when comparing levels of "Time" of 2 and 1 , and 4 and 3. However, for L2 " $5 \mathrm{v}$ 1" a p-value of .017 is obtained: treated stocks in Spain traded in a more volatile situation as opposed to stocks in control group. In addition, a significant p-value is found for L5 (and therefore for L1), although the comparison is between two treated groups. Nevertheless, it is noteworthy that volatility developed to opposite directions in Spain and Italy when comparing time periods 5 and 1.

\section{Conclusions}

The short selling bans of 2011-13 did not contain the price volatility of Spanish and Italian financial stocks that were subjected to trading constraints. Therefore, the target that market authorities had set for the interventions was not accomplished. The results are consistent with the bulk of previous studies on the usefulness of short sale bans to contain stock market volatility. Based on the findings of this and previous studies, ESMA and NCAs should maintain particularly strict criterion according for which to assess the necessity to conduct interventions in order to "correct" the markets. As the SEC chairman Christopher Cox stated earlier in this study, "the costs appear to outweigh the benefits".

However, evidence to support the actions taken by regulators are provided, for instance, by Brunnermeier and Oehmke (2014) who show that financial institutions are vulnerable to predatory short selling through enforced liquidation of long-term asset holdings following the withdrawal of depositors and short-term creditors. As the authors conclude, implications on the resilience of balance sheets may justify temporary restrictions on short selling of fragile institutions. It is also true that the approach of this study solely relies on daily closing prices and linear models, which lead to certain limitations. The alternative ways to assess the impact of short sale constraints have been provided by Bernal et al. (2014), Fung and Draper (1999) and Kolasinski et al. (2013) who focused on trading volume and bid-ask spreads, mispricing of index futures and the information content of prices, respectively. Further, as explained earlier, the generalized linear model was applied to time periods that did not reflect the actual treatment periods.

Nonetheless, it is questionable whether short sale bans or other constraints of similar effect should be justified by excessive volatility for two reasons in particular: volatility is a subjective metric in a sense that market participants tolerate risk differently. Thus, it is impossible for a regulatory body to define an exact moment after which the market becomes too risky or too volatile for everybody or even for the majority of participants, yet the measures are collective in nature. Secondly, financial markets are not a closed system; if the risk level does not satisfy the riskaverse person or entity, they are free to exit specific positions or markets in general, or not to utilize the possibility of free entry in the first place. 


\section{References}

Appel, I., \& Fohlin, C. (2010). 'Shooting the Messenger?' The Impact of Short Sale Bans in Times of Crisis. http://dx.doi.org/10.2139/ssrn.1595003

Australian Securities and Investments Commission (2012). Short Selling: Post-Implementation Review. Retrived from http://asic.gov.au/regulatory-resources/find-a-document/reports/rep302-short-selling-post-implementation-review/

Bai, Y., Chang, E. C., \& Wang, J. (2006). Asset Prices under Short-Sale Constraints. Retrived from https://stuff.mit.edu/people/wangi/pap/BCW 061112.pdf

Baker, M., \& Wurgler, J. (2006). Investor Sentiment and the Cross-Section of Stock Returns. The Journal of Finance 61(4), 1645-1680. https://doi.org/10.1111/j.1540-6261.2006.00885.x

Beber, A., \& Pagano, M. (2013). Short-Selling Bans Around the World: Evidence from the 200709 Crisis. The Journal of Finance 68(1), 343-381. https://doi.org/10.1111/j.1540$\underline{6261.2012 .01802 . x}$

Bernal, O., Herinckx, A., \& Szafarz, A. (2014). Which Short-Selling Regulation is the Least Damaging to Market Efficiency? Evidence from Europe. International Review of Law and Economics 37(c), 244-256. https://doi.org/10.1016/j.irle.2013.12.002

Boehmer, E., Jones, C. M., \& Zhang, X. (2013). Shackling Short Sellers: The 2008 Shorting Ban. The Review of Financial Studies 26(6), 1363-1400. https://doi.org/10.1093/rfs/hht017

Boehmer, E., \& Wu, J. (2013). Short Selling and the Informational Efficiency of Prices. The Review of Financial Studies 26(2), 287-322. https://doi.org/10.1093/rfs/hhs097

Boulton, T. J., \& Braga-Alves. M. V. (2012). Naked Short Selling and Market Returns. The Journal of Portfolio Management 38(3), 133-142. https://doi.org/10.3905/jpm.2012.38.3.133

Boulton, T. J., \& Braga-Alves, M. V. (2010). The Skinny on the 2008 Naked Short Sale Restrictions. Journal of Financial Markets 13(4), 397421. https://doi.org/10.1016/j.finmar.2010.05.002

Bris, A., Goetzmann, W. N., \& Zhu, N. (2007). Efficiency and the Bear: Short Sales and Markets around the World. The Journal of Finance 62(3), 1029-1079. https://doi.org/10.1111/i.1540$\underline{6261.2007 .01230 . x}$

Brown, G. W., \& Cliff, M. T. (2005). Investor Sentiment and Asset Valuation. The Journal of Business 78(2), 405-440. https://doi.org/10.1086/427633

Brunnermeier, M. K., \& Oehmke, M. (2014). Predatory Short Selling. Review of Finance, European Finance Association 18(6), 2153-2195. https://doi.org/10.1093/rof/rft043

Chang, E. C., Cheng, J. W., \& Yu, Y. (2007). Short-Sales Constraints and Price Discovery: Evidence from the Hong Kong Market. The Journal of Finance 62(5), 20972121. https://doi.org/10.1111/i.1540-6261.2007.01270.x

Charoenrook, A., \& Daouk, H. (2005). A Study of Market-Wide Short-Selling Restrictions. Cornell University Working Paper. Retrived from https://papers.ssrn.com/sol3/papers.cfm?abstract id=687562

Christophe, S. E., Ferri, M. G., \& Angel, J. J. (2004). Short-Selling Prior to Earnings 
Announcements. Journal of Finance 59(4), 1845-1875. https://doi.org/10.1111/i.1540$\underline{6261.2004 .00681 . x}$

Committee of European Securities Regulators (2010). Model for a Pan-European Short Selling Disclosure Regime.

Retrived from https://www.esma.europa.eu/sites/default/files/library/2015/11/10 088.pdf

Datta-Chaudhuri, M. (1990). Market Failure and Government Failure. The Journal of Economic Perspectives 4(3), 25-39. https://doi.org/10.1257/jep.4.3.25

Diamond, D. W., \& Verrecchia, R. E. (1987). Constraints on Short-Selling and Asset Price Adjustment to Private Information. Journal of Financial Economics 18(2), 277311. https://doi.org/10.1016/0304-405X(87)90042-0

Dobravolskas, A., \& Seiranov, J. (2011). Financial Stability as the Goal of Post-Crisis Regulatory Reforms. Verslo Sistemos ir Ekonomika 1(1), 101-114.

European Commission (2014). A Comprehensive EU Response to the Financial Crisis: Substantial Progress towards a Strong Financial Framework for Europe and a Banking Union for the Eurozone. Retrived from URL: http://europa.eu/rapid/press-release MEMO-14$\underline{57 \text { en.htm }}$

European Securities and Markets Authority (2011). ESMA Promotes Harmonised Regulatory Action on Short-Selling in the EU. Retrived from https://www.esma.europa.eu/sites/default/files/library/2015/11/esma 2011266 uu pu blic statement on short selling.pdf

Financial Services and Markets Authority (2012). The FSMA Modifies Short Selling Rules. Retrived from http://www.fsma.be/en/Article/press/div/2012/2012-02-13 shortselling.aspx

Fung, J. K. W., \& Draper, P. (1999). Mispricing of Index Futures Contracts and Short Sales Constraints. Journal of Futures Markets 19(6), 695-715. https://doi.org/10.1002/(SICl)10969934(199909)19:6<695::AID-FUT4>3.0.CO;2-H

Gregoriou, G. N. (2011). Handbook of short selling. Waltham, MA, USA: Academic Press.

Hansson, F., \& Fors, E. (2009). Get Shorty? Market Impact of the 2008-09 U.K. Short Selling Ban. University of Gothenburg Working Papers in Economics No. 365. Retrived from https://gupea.ub.gu.se/handle/2077/20407

Hellenic Capital Market Commission (2010). Guidance on HCMC's Decision Regarding Short Selling Ban.

Helmes, U., Henker, J. \& Henker, T. (2011). The Effect of the Ban on Short Selling on Market Efficiency and Volatility. Paper presented at the 2011 Financial Management Association Annual Meeting, Denver. http://dx.doi.org/10.2139/ssrn.1688135

Huang, D., Jiang, F., Tu, J., \& Zhou, G. (2015). Investor Sentiment Aligned: A Powerful Predictor of Stock Returns. Review of Financial Studies 28(3), 791837. https://doi.org/10.1093/rfs/hhu080

Kolasinski, A. C., Reed, A., \& Thornock, J. R. (2013). Can Short Restrictions Actually Increase Informed Short Selling? Financial Management 42(1), 155-181. https://doi.org/10.1111/j.1755053X.2012.01223.X 
Lecce, S., Lepone, A., \& Segara, R. (2008). The Impact of Naked Short-Sales on Returns, Volatility and Liquidity: Evidence from the Australian Securities Exchange. 21st Australasian Finance and Banking Conference 2008 Paper. https://dx.doi.org/10.2139/ssrn.1253176

Lee, W., Jiang, C., \& Indro, D. (2002). Stock Market Volatility, Excess Returns, and the Role of Investor Sentiment. Journal of Banking and Finance 26(12), 22772299. https://doi.org/10.1016/S0378-4266(01)00202-3

Liikanen, E. (2012). High-Level Expert Group on Reforming the Structure of the EU Banking Sector. Final Report. Retrived from http://ec.europa.eu/internal market/bank/docs/highlevel expert group/report en.pdf

Lobanova, O., Hamid, S. S., \& Prakash, A. J. (2010). The Impact of Short-Sale Restrictions on Volatility, Liquidity and Market Efficiency: The Evidence from the Short-Sale Ban in the U.S. http://dx.doi.org/10.2139/ssrn.1571601

McKenzie, M. D. (2012). Should Short Selling Be Banned During Periods of Market Turmoil? JASSA 2, 8-13.

Miller, E. M. (1977). Risk, Uncertainty, and Divergence of Opinion. The Journal of Finance 32(4), 1151-1168. https://doi.org/10.1111/j.1540-6261.1977.tb03317.x

Moloney, N. (2014). EU Securities and Financial Markets Regulation. Oxford University Press.

Moon, C.-G., \& Stotsky, J. G. (1993). The Effect of Rent Control on Housing Quality Change: A Longitudinal Analysis. Journal of Political Economy 101(6), 11141148. https://doi.org/10.1086/261917

Quaglia, L. (2007). The Politics of Financial Services Regulation and Supervision Reform in the European Union. European Journal of Political Research 46(2), 269290. https://doi.org/10.1111/j.1475-6765.2006.00695.x

Reed, A. V. (2002). Costly Short-Selling and Stock Price Adjustment to Earnings Announcements. Dissertations available from ProQuest. AAl3073047. Retrived from http://repository.upenn.edu/dissertations/AAI3073047

Saastamoinen, J., \& Suhonen, N. (2013). Were the European Short Selling Bans of 2011 Effective? Economics Bulletin 33(3), 1847-1851. Retrived from http://www.accessecon.com/Pubs/EB/2013/Volume33/EB-13-V33-I3-P173.pdf

Saffi, P. A. C., \& Sigurdsson, K. (2011). Price Efficiency and Short Selling. The Review of Financial Studies 24(3), 821-852. https://doi.org/10.1093/rfs/hhq124

Securities and Exchange Commission (2008). SEC Halts Short Selling of Financial Stocks to Protect Investors and Markets. Retrived from http://www.sec.gov/news/press/2008/2008211.htm

Setzu, A., \& Marchesi, M. (2006). The Effects of Short-Selling and Margin Trading: A Simulation Analysis. University of Cagliari Working Paper. Retrived from https://www.semanticscholar.org/paper/The-Effects-of-Short-Selling-and-MarginTrading-a-Setzu-Marchesi/e4a412a782035b8141ed641d4c0e19b596fed2b1

Vitali, S., Glattfelder, J. B., \& Battiston, S. (2011). The Network of Global Corporate Control. PloS One 6(10). https://doi.org/10.1371/journal.pone.0025995 
Werner, S. (2010). Short Selling Activities and Convertible Bond Arbitrage - Empirical Evidence from the New York Stock Exchange. Vol. 75. Springer Science \& Business Media. https://doi.org/10.1007/978-3-8349-6003-0 